\title{
On the Vision of Basketball Players
}

\author{
Junhao Zhao, Guanghui Guo \\ Hubei Water Resources Technology College, Wuhan, China (1zhao899@gmail.com)
}

\begin{abstract}
In basetball teaching and training, many teachers/coaches often overlook the vision practice of students or players. The limited vision affects the technical and stratigical level of the whole team. In this study, I conducted systematical and scientific analyses on the character of basketball players' vision, the effecting factors of vision, and raised some suggestions for training.
\end{abstract}

Keywords - vision, characters of vision, effecting factors, training suggestions

\section{浅谈篮球运动员的视野}

\author{
赵俊浩郭广辉
}

湖北水利水电职业技术学院, 武汉, 湖北, 中国

\begin{abstract}
摘 要 在篮球教学与训练中往往忽视了大学生或运动员的视野练习, 造成视野能力的局限而影响了全队的技、战术水平的提高。 在这里我们将对篮球运动员视野的特点, 影响因素进行科学、系统的分析, 并提出一些训练建议。
\end{abstract}

关键词 视野, 视野的特点, 影响因素, 训练建议

\section{1. 篮球运动员视野的特征}

\section{1 广阔性}

视野是指双目在相对静止状态下, 两视轴平行时所看 到的范围。篮球运动员的视野是指在比赛中运动员在一瞬 间能观察到场上情况及变化范围, 行动及时、反应敏捷的 作出合理的技术动作。由此可见观察是形成视野的行动, 篮球运动中的观察与一般的观察有所不同, 一般观察大多 是注视, 只对视野内某事物进行观察, 而篮球运动中特有 的观察是对多个事物同时或先后发生的情况进行观察, 包 括球场内外整个立体空间的一切事物。对方队员、同队队 员、球篮板、场地以及教练、裁判观众等。因此, 篮球运 动员的视野强调其广阔性。

篮球比赛双方的争夺是在至少 $28 \times 15 \times 7=2940 \mathrm{~m} 3$ 的立 体空间进行, 为了战术的需要, 队员不停的移动, 球不停的 传递, 攻防转换瞬息万变攻防的机会如配合都不可能只在 一个点上出现。它可能出现在场上的任何一个“点”, 也可 能在场上若干“点”同时出现, 这就要求篮球运动员具有广 阔的视野。例如: 篮球比赛中, 控球队员应随时观察到四 个同伴及防守队员的活动情况, 以便任何一名同伴出现战 机时, 准确及时地传出球, 从而进攻得手。如果控球队员
只看到一两名同伴的活动情况, 无疑会遗漏许多进攻良机。 因此, 视野的广阔性是篮球运动员进行观察所必备的首要 特点。

\section{2 隐蔽性}

篮球运动中各种技、战术隐蔽性的作用, 是不可忽视 的, 而观察事物的隐蔽性是形成技、战术隐蔽性的前提。 如在进攻时, 持球队员可以用视线、突破、投篮等把防守 队员的注意吸引到自己身上, 而将球迅速准确地传给用余 光观察到的处于有利位置的另一同伴, 使对方措手不及, 达到“声东击西”的效果。这就要求篮球运动员在技战术上 灵活宽广虚虚实实, 为了加强观察的隐蔽性, 运动员的观察 方式应是充分利用余光观察。

\section{3 迅速性}

现代篮球运动的战术配合攻防转换速度都在加快, 比 赛场上的情况瞬间就会发生变化, 战机出现的时间很短促, 如果观察延误, 一次机会即刻失去, 运动员只有具备敏锐 的观察力才能及时捕捉到各个战机。例如: NBA 比赛中经 常可以看到, 在比赛结束前几秒, 甚至一秒钟之间完成进 
攻配合投篮得分。如果没有迅速的观察力是不可能抓住关 键战机的。

\section{4 动态性}

篮球运动本身就是动态的, 观察的对象包括运动员本 身都在不停的发生变化, 位置的跑动、球的转移、攻转守、 守转攻等等, 双方的运动势必会影响观察的准确性, 所以, 运动员必须具备在静中观察动态, 在动中观察静态的特有 观察力, 才不至于导致观察结果失真。例如: 长短传快攻 时, 传球队员的奔跑速度, 路线直接影响传球的落点, 落 点的选择是否正确应结合自己同伴奔跑速度和防守动态来 定论, 此时在行进当中及时准备的捕捉到进行配合的关键 点, 即成为取胜的前提。如果运动员延误了任一个观察要 素则会导致传球不到位或不及时。因此, 观察的动态性是 运动员视野能力一个基本特点。

\section{5 综合性}

人的视野是有一定自然条件限制的, 运动在比赛场上 往往以一个角度不可能观察到全局的情况, 只有借助于眼 珠、头颈, 脚步变化甚至身体的转动, 以不同的角度来观 察, 并将其先后观察的孤立情况有机的联系起来, 才能感 知全局情况, 即运动员只有将前一个视野观察的情况通过 思维对其发展趋势作出正确的判断, 并与这一次视野观察 的情况相结合, 在大脑中形成连续的情势运动图象。新视 野内的情况与前面的系列旧视野内的情况通过思维有机的 结合, 在运动员头脑中形成了全场的动态图, 在此基础上, 运动员才可对全局形势的发展迅速作出正确的估计, 为自 已下一步战术行动作好准备, 这就是观察与思维相结合而 构成的篮球运动员特有的专项视野。

\section{2. 影响篮球运动员视野的因素}

2.1 篮球运动员生理机制对视野的影响

从解剖学角度来看, 人的两眼在头的前部, 只能看见 前面的事物。从生理学来看, 当眼前看到 $6 \mathrm{~m}$ 以外的东西 时, 两眼的视轴是平行的, 随着目标的移近, 视轴逐渐向 鼻中线会聚, 视野也随之缩小。而篮球比赛是短兵相接的 近战, 而且人们观察天生习惯于注视, 这无疑使视野的范 围受到了影响。

当然, 近视野对视野的影响也是不可忽视的。近视眼 看事物一般都是聚光注视, 即要看清事物就要眯眼聚光才 行, 而且由于视力本身就差, 余光观察的能力就更差了, 这样大大的影响了视野的范围。

\section{2 篮球运动员技术对视野的影响}

心理学告诉我们, 人在同时间内做到“一心二用”是可 能的, 其生理机制是: 支配当前主要活动的是大脑皮质的 优势兴奋中心，支配那些熟练活动的相应区域处于一定程 度的抑制状态, 在几种活动中必须使其中一种活动技能达 到“自动化”的程度，才有可能同时进行其它工作，这就是 注意的可分配性, 例如: 运动员球性不熟, 在运球时就要 在控球上集中“注意”, 甚至有的还要低头看球才能控制球, 这样就不可能把“注意”集中用来观察, 影响视野能力。所 以，应该把观察作为集中“注意”的活动，而把技术动作变 为相对“自动化”的活动来扩大视野范围, 捕捉更多的战机。 篮球运动员的战术意识、跑位能力、传球的准确性及其任 何一项个人技术的应用,首先取决于运动员是否有快速准 确地处理所接受视觉信号的能力, 这种能力又取决于运动 视觉器官的发育程度和训练水平, 取决其视觉与运动系统 相互协调的训练程度,许多的成功与失误应把它归纳入 “眼 睛运动”视野。

\section{3 篮球运动员战术意识的影响}

优秀篮球运动员视野开阔, 新手视野狭窄, 之所以产 生这种现象是由于他们之间战术意识的显著差别所造成的 “有效视野”的差异。篮球比赛对抗激烈, 如果运动员能熟 练掌握许多种战术配合、较强的战术意识, 那么不管场上 如何变化, 运动员都能选择最佳位置把更多的“关键点”纳 入视野范围。他们进攻时能“穿透”防守人来观察了解全场 情况,作出正确的判断, 不放掉任何处于最佳位置的同伴得 分; 他们防守时能用宽广的视野合理调整自己在球、对手、 球篮之间的位置, 作出正确的判断和行动, 阻止对方得分, 或快速抢断得分。

\section{3. 结论}

在日常生活和训练中, 注意改善视觉习惯, 锻炼视轴 扩散, 以获得较宽注意分配的广度。特别要提高余光观察 的能力。例如: 做眼睛顺逆时针方向的转动。

加强眼珠、头部、脚歩动作及身体转动的灵活性, 提 高快速、灵活的观察能力。例如: 三人结成等边三角形传 球, 从传一球逐渐增加至同时传三个球。右手摸右脚转头 看右边,左手摸左脚转头看左边等。

习惯于观察动态事物, 特别是在运动中观察周围动态。 例如: 进行两人至三人短传全场上篮练习, 在途中逐步增 设障碍物, 运动员进行中注意避开特设的障碍物。

加强技术训练, 使运动员达到“自动化”程度。例如: 为加强控制球能力而进行多球运球、蒙眼运球等。 
熟练掌握多种战术, 培养良好的战术意识扩大“有效视 野”范围,观摩国内外高水平的篮球比赛等。

\section{参考文献(References)}

[1] Y. Guoxiong and C. Shuhua, Basketball Research Reading. Beijing, China: People's Sports Publishing House of China, 1999
[2] L. Yudong, the Modern Technics of Basketball Teaching and Training. Beijing, China: Beijing Sports University Press, 1992

[3] The textbook Committee of National Institutes of Physical Education, the Textbook for Institutes of Physical Education-Basketball. Beijing, China: People's Sports Publishing House of China, 1991 